Geochronology

\section{Diamond dating anomalies}

\author{
Martin H. Dodson
}

DIAMONDS are particularly interesting samples of the Earth's mantle. Because of their unique combination of chemical stability and mechanical strength, impurities which they incorporate at their birth are protected almost indefinitely against interactions with the surrounding mantle. Some diamonds are known to be $2-3$ thousand million years (Gyr) old ${ }^{1,2}$, but direct dating of diamonds by the potassium-argon method has not been attempted until fairly recently ${ }^{3.4}$, despite the great sensitivity of modern equipment for argon isotope analysis. Expectations, however, in geochronology are easily confounded; Ozima and co-workers, in a series of papers ${ }^{4-6}$ culminating in the one on page 226 of this issue ${ }^{6}$, show that forming diamonds can incorporate large amounts of 'excess' radiogenic argon in association with potassium, so that what began as a dating project has ended as a study of ancient mantle fluids.

Because of previous indications that excess argon would be a problem ${ }^{3}$, Ozima and his colleagues decided to use an 'isochron' method (see figure) to date a suite of ten samples from Zaire called 'cubic' diamonds. These curious stones are polycrystalline aggregates with a rather fibrous structure and roughly cubic in shape, some having clear octahedral cores. It seemed likely that they are of uniform age and share the same initial argon isotope composition, essential conditions for the isochron method. In the event the stones yielded ${ }^{4}$ a respectable linear array on the potassium-argon isochron diagram - indicative of uniform age - but a thoroughly unrespectable age of $6 \mathrm{Gyr}$, apparently making them $1.5 \mathrm{Gyr}$ older than the Solar System.

Obtained from a single sample, this result would simply have been rejected as being due to excess radiogenic argon. The linearity of the isochron plot, however, made such an idea hard to accept, for it required that the excess argon was incorporated in exact proportion to the potassium. This seemed unlikely, because normally the contrast in chemistry between potassium and argon ensures that the $\mathrm{Ar} / \mathrm{K}$ ratio in a new mineral grain is both lower (commonly zero) and more variable than in its surroundings.

A more fundamental explanation was therefore sought, and it was suggested that the potassium had an anomalously high abundance of the parent ${ }^{40} \mathrm{~K}$. However, it was soon shown ${ }^{5}$ that potassium in Zaire diamonds is isotopically indistinguishable from that found in any other terrestrial material. Thus the diamonds must either have incorporated a pre-solar component (diamonds have been found in meteorites) or have been isotopically contaminated in a very unusual way.

The question is now resolved in this issue ${ }^{6}$ in favour of contamination during crystal growth, by mechanical entrapment of an argon-rich fluid. The clinching evidence comes from the argon-argon (or argon-39) method, in which samples are irradiated with fast neutrons, converting a small proportion of ${ }^{39} \mathrm{~K}$ to ${ }^{39} \mathrm{Ar}$. The ratio ${ }^{40} \mathrm{Ar} /{ }^{39} \mathrm{Ar}$ in gas extracted from the

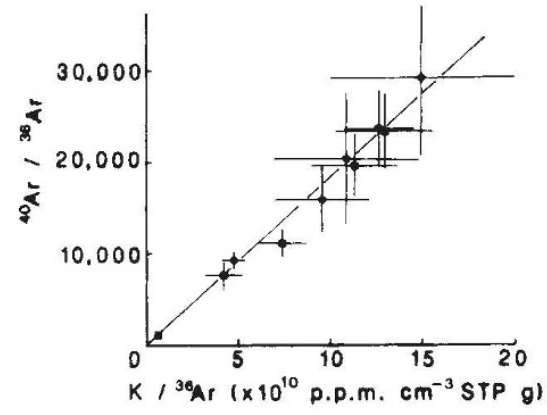

Isochron plot for cubic diamonds from the earlier paper by Ozima and co-workers ${ }^{4}$. The ${ }^{40} \mathrm{Ar}$ and $\mathrm{K}$ contents of samples are plotted as ratios to their ${ }^{36} \mathrm{Ar}$ contents, which are assumed to be constant through time. Because ${ }^{40} \mathrm{~K}$ decays radioactively to ${ }^{40} \mathrm{Ar}$, data from samples formed at the same time, with uniform 'initial' argonisotope composition $\left({ }^{40} \mathrm{Ar} /{ }^{36} \mathrm{Ar}\right)$, but variable $\mathrm{K} /{ }^{36} \mathrm{Ar}$, would all fall on a straight line whose slope gives the age of the samples. The intercept shows the initial ${ }^{40} \mathrm{Ar} /{ }^{36} \mathrm{Ar}$, in this case close to zero $(-700 \pm 900)$, suggesting that no ${ }^{40} \mathrm{Ar}$ was trapped in the forming diamonds. The ${ }^{39} \mathrm{Ar}$ data of Ozima and co-workers in this issue, however, show that these diamonds entrapped, as they grew, a variable mixture of fluids, one with high, fairly uniform $\mathrm{Ar} / \mathrm{K}$, another with $l o w^{40} \mathrm{Ar} /{ }^{36} \mathrm{Ar}$.

samples corresponds to the radiological daughter-parent ratio ${ }^{40} \mathrm{Ar} /{ }^{40} \mathrm{~K}$ in the conventional method. The gas is usually extracted in stages while the sample is heated to successively higher temperatures; changes in apparent age during this step-heating procedure show differences between the locations of ${ }^{40} \mathrm{Ar}$ and ${ }^{39} \mathrm{Ar}$ within the sample. (Furthermore, during neutron irradiation ${ }^{38} \mathrm{Ar}$ is produced from chlorine and ${ }^{37} \mathrm{Ar}$ from calcium, so the concentrations of these elements may also be determined by argon isotope analyses.)

In their new paper, Ozima et al ${ }^{6}$ present step-heating analyses of four irradiated diamond samples. The 'age' from their isochron plot is again close to $6 \mathrm{Gyr}$, with little indication of changes during stepheating. More important, they find an excellent correlation of chlorine with ${ }^{410} \mathrm{Ar}$. Ozima et al. point out that similar correlations obtained from fluid inclusions in the upper crust reflect leaching of argon and chlorine from crustal rocks. Evidently these diamonds provide evidence for analogous processes in the mantle, and the gases extracted from them consist of mixtures, in varying proportions, of a chlorine-free component with ${ }^{40} \mathrm{Ar} /{ }^{36} \mathrm{Ar}$ of about 340 and a component with ${ }^{40} \mathrm{Ar} / \mathrm{Cl}$ of 8 or 9 . Rather less convincing is the attempt, by means of a correlation diagram for radiogenic ${ }^{40} \mathrm{Ar} / \mathrm{K}$ against $\mathrm{Cl} / \mathrm{K}$, to separate the ${ }^{40} \mathrm{Ar}$ into an excess component and an in situ radiogenic component (with a calculated age in the range $0-3$ Gyr).

Navon et al. ${ }^{7}$ (see also ref. 8) recently presented elemental analyses for Zaire cubic diamonds rich in sub-micrometre inclusions, interpreting them in terms of volatile-rich fluids roughly comparable with potassic magmas. Ozima et al. give potassium, chlorine and calcium abundances which are broadly consistent with those of Navon et al., and provide complementary argon-isotope data. The significance of these inclusions for the understanding of mantle processes ${ }^{8}$ would be hard to exaggerate, and it is clear that there must be further attempts to date them. Reported success in dating of fluid inclusions in crustal rocks ${ }^{9}$ suggests that the $\mathrm{Rb}-\mathrm{Sr}$ method could be worth a try.

Finally, do the problems encountered in dating of diamonds have serious implications for more conventional applications of the potassium-argon method? The answer is, probably not. In these diamonds the potassium-argon system is evidently dominated by a rather homogeneous ${ }^{40} \mathrm{Ar}$-rich fluid which has been incorporated mechanically during crystal growth, mixed with small amounts of a low ${ }^{40} \mathrm{Ar}{ }^{36} \mathrm{Ar}$ component. Thus the system does not satisfy one of the most fundamental requirements for successful dating, that the radiometric clock must be reset by a process of chemical differentiation between parent and daughter elements. In ordinary rocks and minerals the immense difference between the chemical properties of potassium and argon ensures that this condition can usually be satisfactorily met, with the likelihood of obvious inconsistencies in the data if it is not.

1. Kramers, J.D. Earth planet. Sci. Lett. 42, 58-70 (1979)

2. Richardson, S.H., Gurney, J.J., Erlank, A.J. \& Harris, J.W. Nature 310, 198-202 (1984)

3. Ozima, M., Zashu, S. \& Nitoh, O. Geochim. cosmochim. Acta 47, 2217-2224 (1983).

Zashu, S., Ozima, M. \& Nitoh, O. Nature 323, 710-712 (1986)

5. Podosek, F. A. et al. Nature 334, 607-609 (1988).

6. Ozima, M., Zashu, S., Takigami, Y. \& Turner, G. Nature 337, 226-229 (1989)

. Navon, O., Hutcheon, I.D., Rossman, G.R. \& Wasserburg, G.J. Nature 335, 784-789 (1988)

8. Menzies, M. A. Nature 335, 769-770 (1988)

9. Darbyshire, D.P.F. \& Shepherd, T.J. J. geol. Soc. Lond. 142. 1159-1177 (1985).

Martin H. Dodson is in the Department of Earth Sciences, University of Leeds, Leeds LS2 9JT, $U K$. 